\title{
Assessment of neonatal mortalities and stillbirths data quality in Offinso North District of Ghana
}

\author{
Richmond Nsiah ${ }^{1 *}$, Wisdom Takramah ${ }^{2}$, Solomon Anum-Doku ${ }^{1}$, Richard Avagu ${ }^{3}$, Dominic Nyarko ${ }^{4}$ \\ ${ }^{1 *}$ Asokore Mampong Municipal Health Directorate, Ashanti, Ghana \\ ${ }^{2}$ School of Public Health, University of Health and Allied Sciences, Ho, Ghana \\ ${ }^{3}$ Offinso North District Health Directorate, Ashanti, Ghana \\ ${ }^{4}$ Suntreso Government Hospital, Ashanti, Ghana
}

\begin{abstract}
Background: Stillbirths and neonatal deaths when poorly documented or collated, negatively affect the quality of decision and interventions born out of these data. This study sought to assess the quality of routine neonatal mortalities and stillbirth records in health facilities and propose interventions to improve data quality gaps.

Method: Descriptive cross-sectional study was carried out at three (3) purposively selected health facilities in Offinso North district. Stillbirths and neonatal deaths recorded in registers from 2015 to 2017, were recounted and compared with monthly aggregated data and District Health Information Management System 2 (DHIMS 2) data using a self-developed Excel Data Quality Assessment Tool (DQS). An observational checklist was used to collect primary data on completeness and availability of selected variables. Accuracy ratio (verification factor), discrepancy rate, percentage availability and completeness of stillbirths and neonatal mortality data were computed using the DQS tool.
\end{abstract}

Findings: The results showed high discrepancy rate of stillbirth data recorded in registers compared with monthly aggregated reports (12.5\%), and monthly aggregated reports compared with DHIMS $2(13.5 \%)$. Neonatal mortalities data were under-reported in monthly aggregated reports, but over-reported in DHIMS 2. Overall data completeness was about $84.6 \%$, but only $68.5 \%$ of submitted reports were supervised by facility in-charges. Delivery and admission registers availability were $100 \%$ and $83.3 \%$ respectively.

Conclusion: Quality of stillbirths and neonatal mortality data in the district is generally encouraging, but are not reliable for decision-making. Routine data quality audit should be instituted to reduce high discrepancies in stillbirth and neonatal mortality data.

Keywords—Stillbirth, Neonatal, Data Quality, Data Completeness, Data Accuracy, Data Availability, Data Storage

\section{Introduction}

Data is the primary foundation in operational, tactical and decisions making activities. Data are crucial resources and its quality is critical for managers and operating processes to identify related performance issues (Sidi et al., 2013). In this era, all the technical and strategic decision are data driven. In order to make perfect judgements and add value to organization, quality of data must be consistent. Data quality can be defined in many ways but data generally is considered quality, if the data are fit for their intended uses in operations, decision making and planning by managers (Patel, 2015). In health-care sector, poor capturing of client's data can lead to incorrect diagnoses, with fatal consequences. Decadent data can also waste resources and damage an organization's reputation as a result of bad decision making (Mouroutis, 2015). Many West African countries with disproportionately high perinatal mortality rates often have weak data management and health systems, resulting in a paucity of perinatal morbidity and mortality information and 
a deficiency in the availability of high-quality data (Engmann et al., 2012). The World Health Organization (WHO) defines stillbirth, as a baby born dead at 28 weeks of gestation or more, with a birth weight of $\geq 1000$ $\mathrm{g}$, or a body length of $\geq 35 \mathrm{~cm}$ and neonatal deaths, as deaths occurring within the first 28 days of life (World Health Organization (WHO), 2016). Stillbirths and Neonatal mortalities that occur in the health facilities are captured in the delivery register which serves as the source document at the Maternity Unit, from which figures are tallied and transferred onto the aggregated form called Monthly Midwife Report (Form A) for further reporting to the next level. However, managers who make decisions are not able to ascertain the accurate numbers of stillbirths and neonatal deaths that occurred at the facilities. It is either under-reported or over-reported by these health facilities thereby affecting decisions making of managers due to inaccurate data. These errors in data collection, can be due to limited resources for data collation, lack of clarity on indicators, lack of training, inadequate manpower, and non-adherence to standard operating procedures amongst others.

Offinso North District has eight (8)-health facilities, which are located under five health-demarcated subdistricts with assigned administrative heads. All health facilities are mandated to collate, validate and transmit all applicable monthly aggregated reports into the District Health Information System 2 (DHIMS 2) before the fifth of ensuing month. Discrepancies in data normally occur during tallying from the registers and collating onto the aggregated form. The 2017 first quarter Outreach Training and Supportive Supervision (OTSS) exercises revealed noticeable data discrepancy between tallied stillbirths and neonatal mortality data from delivery registers and the facility-aggregated data submitted to the District Health Directorate. Low accuracy of stillbirth and neonatal mortality data entered into DHIMS2, inadequate knowledge and lack of skills in ICT by data managers were some of the challenges encountered as captured in the OTSS first quarter report of the district (Ghana Health Service, 2019). Offinso North District Health Directorate in 2017, recorded a total of 3 stillbirths from Facility A as recorded in DHIMS2 but the monthly midwives returns submitted to the district level witnessed great discrepancies in terms of stillbirths and neonatal mortalities for the same years (Ghana Health Service, 2017). These disparities gave an indication that stillbirths and neonatal mortalities data, are not accurately captured and collated by health facilities. This study therefore sought to assess the quality of data on routine neonatal deaths and stillbirths for 2015 to 2017 in Offinso North District in the Ashanti Region of Ghana.

\section{Materials and Methods \\ Study site description}

This study was conducted at labour and in-patient units of the three selected health facilities in Offinso North District. The district has a projected population and expected delivery of 68,193 and 2,728 respectively. It has five demarcated sub-districts and about Eighty-Six (86) communities. The district has two (2) CHAG facilities, One (1) private facility and five (5) public health facilities.

\section{Study population}

The study population comprised all neonatal deaths and stillbirths recorded between January 2015 and December 2017 in the three-selected health facilities in Offinso North District.

\section{Inclusion Criteria}

All stillbirths and neonatal deaths data recorded from January 2015 to December 2017 and documented in the delivery and admission registers were included in the study.

\section{Exclusion criteria}

All delivery and admission registers that contained stillbirths and neonatal deaths data recorded from January 2015 to December 2017 which were missing or unavailable at the time of data collection were excluded from the study.

\section{Study design}

This study employed a descriptive cross-sectional study to collect secondary data on accuracy and discrepancy and primary data on completeness and availability of selected stillbirth and neonatal mortality 
variables. This type of descriptive study was considered useful because it provided a quick snapshot of the nature of the variables of interest for the study and it was relatively inexpensive.

\section{Sample size determination}

Stillbirths and neonatal mortality data recorded in delivery and admission registers, from January 2015 to December 2017 by health facilities, which initiated maternity services in the same period, were sampled for the study.

\section{Sampling method}

All three (3)-health facilities that initiated maternity services and reported into DHIMS 2 from January 2015 to December 2017 were purposive sampled for the study.

\section{Data collection procedure}

Microsoft Excel 2016 based Data Quality Self-Assessment Tool (DQS) and Observation checklist were used to review stillbirth and neonatal mortality data from $20^{\text {th }}$ March to 18th April 2019. The pre-test of the data collection instruments was done outside the study area at two (2) health facilities with the same characteristics as the sampled health facility. The necessary corrections were made to the data collection instruments, which were subsequently administered at the maternity unit of the sampled health facilities.

Data Quality Self-Assessment (DQS) tool was used to check for data accuracy and data discrepancy. Stillbirth and neonatal mortalities data recorded in both delivery and admission registers, were recounted and compared with data reported on Monthly Midwives Return to ascertain accuracy and discrepancies levels. Stillbirths and neonatal mortalities transcribed onto Monthly Midwives Return and data entered into DHIMS 2 were further compared for the periods under review.

The observation checklist was administered to capture data on the availability, storage and completeness of delivery, admission and discharged registers as well as Monthly Midwives Returns. The completeness part of the checklist was categorized into two main parts namely; "missing data" and "report submission". The missing data aspect collated data on whether facility name, reporting period, submission date, name and signature of facility head were indicated on the Monthly Midwives Returns. The second part labelled "report submission" collated data on the complete submission of Monthly Midwives Returns and DHIMS 2 reports. A follow up to the District Health Directorate was made to confirmed hard copy submission, availability and storage of Monthly Midwives Return submitted by these three (3) health for the period under review.

\section{Data analysis}

Data entry, processing and analysis was done using Data Quality Self-Assessment Tool (DQS). The DQS tool captured the month from January to December from 2015 to 2017 with its corresponding data collated from all data sources for the various facilities assessed. The DQS was pre-coded to automatically generate accuracy ratio and discrepancy rate after completely filling the DQS template with data collated from the various data sources.

The accuracy ratio (data verification factor) was defined as the ratio between the number of stillbirth and neonatal mortalities recounted from a source registers (numerator), compared to the number of stillbirth and neonatal mortalities reported by that facility to higher levels (denominator) expressed as a percent. Accuracy ratio of less than $(<) 100$ percent was considered over reported. Accuracy ratio greater than $(>) 100$ percent was considered under reported. An accuracy ratio of $100 \%$ was considered as excellent performance. Accuracy ratio between $80 \%$ and $99 \%$ was considered as good performance and below $80 \%$ was graded as poor performance. Any data with discrepancy rate more than $10 \%$ was considered not reliable for decisionmaking. The higher the discrepancy rate, the less quality the data become. The formula for generating the accuracy ratio and discrepancy rates has been expounded below:

- $\operatorname{Accuracy}$ ratio $(\mathbf{A R})=$

AR 1: (Total recounted data from register $\div$ monthly aggregated data) $\times 100$ 
AR 2: (Monthly aggregated data $\div$ DHIM2 data) $\times 100$

- $\quad$ Discrepancy rate $(\mathbf{D R})=$

DR 1: $100-$ AR 1

DR 2: 100 - AR 2

The collated data on availability, storage and data completeness were entered into other section of the Microsoft Excel 2016 based DQA tool to compare the actual number of data available against the expected. The DQA automatically generated percentage score, frequency tables, and graph for data completeness, availability and storage. Softcopies of final data used was securely stored in Dropbox (an online data storage database) and on external drives for future easy retrieval.

\section{Results and Discussion}

This study sought to assessed availability, completeness and accuracy of stillbirths and neonatal mortalities data in the Offinso North District.

\section{Data accuracy of stillbirth and neonatal mortalities Stillbirth}

This study revealed $100 \%$ stillbirth data accuracy by Facility C when source registers were verify with monthly aggregated reports whilst Facility B recorded the lowest score $(60 \%)$ for the same verification factor as depicted on Table 1.

Our study findings highlighted an overall stillbirth accuracy of $87.5 \%$, for data recorded in registers compared with the monthly aggregated reports or Form A for the three (3) facilities used for the study. Our study result is far higher than a study conducted in Northeast India, which revealed about $2 \%$ accuracy between registers and aggregated reports. Our findings further contradicts the documented interpretation in Northeast India's study, which concluded that stillbirths were underreported. (Kusre \& Baruah, 2016). However this present study supports a study done in Ethiopia which documented that stillbirths were over reported (Lindtj et al., 2018). Our study further revealed that no dataset for documenting stillbirth data was $100 \%$ accurate. This finding may be explain by the idea that, there were discrepancies born out of the transcription of data from the delivery register unto the monthly aggregated reports. Students on internships between 2015 and 2017 with little or no idea about standard operative procedures of service delivery data collation were mainly assigned to transcribe all stillbirth data from source register unto the monthly aggregated reports hence these obvious discrepancies. The current level of accuracy between the source register and monthly aggregated reports were further blame on inadequate staff at the various health facilities included in this study.

Our findings further highlighted an accuracy of $86.5 \%$ when stillbirths' data captured on monthly aggregated reports were verify with data entered into DHIMS 2.

The result of the present study is consistent with a research conducted to test the validity and reliability of self-reported stillbirth data linked to state-based administrative datasets (Hure et al., 2015). Whereas a past researcher has found an average accuracy rate of $100 \%$ for stillbirth data capturing (Davies-tuck et al., 2017), the result from this present study has shown an average stillbirths data accuracy of $87 \%$. The result of this current study provides evidence that no data source for reporting stillbirths is accurate (Kusre \& Baruah, 2016). Taken together, the present study indicated an average discrepancy rate of $13 \%$ for all data sources verified. This result is far higher than findings documented in another research (Amoakoh-coleman et al., 2015). 
Table 1. Stillbirths' data accuracy and discrepancy by sampled facilities, Offinso North District, 2015 - 2017

\begin{tabular}{|c|c|c|c|c|c|c|c|c|c|c|}
\hline \multirow[t]{2}{*}{$\begin{array}{l}\text { Health } \\
\text { Facility }\end{array}$} & $\begin{array}{l}\text { Reg } \\
\text { ister }\end{array}$ & $\begin{array}{l}\text { Month } \\
\text { ly } \\
\text { Midwi } \\
\text { ves } \\
\text { Return } \\
\text { s } \\
\end{array}$ & $\begin{array}{l}\text { Accuracy } \\
\text { Ratio (\%) }\end{array}$ & \multirow[t]{2}{*}{$\begin{array}{l}\text { Result } \\
\text { Interpreta } \\
\text { tion }\end{array}$} & $\begin{array}{c}\text { Discrep } \\
\text { ancy } \\
\text { Rate } \\
(\%)\end{array}$ & $\begin{array}{c}\text { Monthl } \\
\text { y } \\
\text { Midwiv } \\
\text { es } \\
\text { Returns }\end{array}$ & $\begin{array}{c}\text { DHIM } \\
\text { S2 }\end{array}$ & $\begin{array}{l}\text { Accura } \\
\text { cy } \\
\text { Ratio }\end{array}$ & \multirow[t]{2}{*}{$\begin{array}{l}\text { Result } \\
\text { Interpreta } \\
\text { tion }\end{array}$} & $\begin{array}{l}\text { Discrepa } \\
\text { ncy Rate }\end{array}$ \\
\hline & [A] & [B] & $\begin{array}{l}(\mathrm{A} / \mathrm{B}) \\
* 100[\mathrm{C} 1]\end{array}$ & & $\begin{array}{l}{[100-} \\
\text { C1] }\end{array}$ & [B] & [C2] & $\begin{array}{l}(\mathrm{B} / \mathrm{C}) \\
* 100 \\
{[\mathrm{C} 2]}\end{array}$ & & $\begin{array}{l}{[100-} \\
\text { C2] }\end{array}$ \\
\hline $\begin{array}{l}\text { Facility } \\
\text { A }\end{array}$ & 23 & 25 & 92 & OR & 8 & 25 & 29 & 86.2 & OR & 13.8 \\
\hline $\begin{array}{l}\text { Facility } \\
\text { B }\end{array}$ & 3 & 5 & 60 & OR & 40 & 5 & 6 & 83.3 & OR & 16.7 \\
\hline $\begin{array}{l}\text { Facility } \\
\text { C }\end{array}$ & 2 & 2 & 100 & AR & 0 & 2 & 2 & 100 & $\mathrm{AR}$ & 0 \\
\hline Total & 28 & 32 & 87.5 & OR & 12.5 & 32 & 37 & 86.5 & OR & 13.5 \\
\hline
\end{tabular}

$\boldsymbol{A}=$ recounted data from register (primary source), $\boldsymbol{B}=$ facility monthly aggregated report, $\boldsymbol{C}=$ data reported in DHIMS2, $\boldsymbol{A} \boldsymbol{R} \mathbf{I}=$ percentage accuracy between primary source and monthly aggregated reports, $\mathbf{A R} \mathbf{2}=$ percentage of accuracy between monthly aggregated reports and DHIMS 2, DRI= percentage discrepancy between primary source and monthly aggregated reports, $\mathbf{D R} \mathbf{2}=$ the percentage discrepancy between monthly aggregated reports and DHIMS 2, Under-reporting = Recounted data is greater than (>) $100 \%$ of facility summary Reported data, Over- reporting=Recounted data is less than $(<) 100 \%$ of the facility summary Reported data, Over reporting=Recounted data is less than $(<) 100 \%$ of the facility summary Reported data, $\mathbf{A R}=$ Accurate Reporting, $\mathbf{U R}=$ Under Reporting, $\mathbf{O R}=$ Over Reporting

\section{Neonatal mortality}

Facility A and Facility B recorded an accuracy rate of $100 \%$ for neonatal mortality data recounted from source registers compare with Monthly Form A reports As illustrated on Table 2. It should be noted that, Facility A could not produce admission and discharge register for 2015. So zeros (0) were recorded for all twelve months of 2015 during compilation of neonatal mortality data for the facility. Though, no neonatal mortality was recorded from January to December 2015 on monthly aggregated reports and DHIMS 2 database after thorough check, we cannot confirm there was no mortality captured in the admission and discharge register for 2015 which was missing during data collection. This may affect the true picture of neonatal mortality accuracy of Facility A. Facility $\mathrm{C}$ recorded one neonatal mortality in the admission and discharge register, but transcribed zero (0) onto the monthly aggregated reports. This resulted in the facility scoring $100 \%$ discrepancy rate for register data against monthly aggregated reports. Facility A recorded no case of neonatal mortality in the registers for period under review but ended up inputting one neonatal mortality into DHIMS 2 database. Facility $\mathrm{C}$ on the other hand recorded one neonatal mortality in register, but failed to transcribe the said mortality unto the Monthly Form A, but ended up inputting one neonatal mortality into DHIMS 2 database.

Our current study highlighted overall discrepancy rate of $100 \%$ for neonatal mortality between all data sources verified as depicted on Table 2. This discrepancy was attributed to over reporting of neonatal mortalities data in DHIMS 2 database. This reason of over reporting in this present finding is not consistent with another study conducted in Ethiopia (Lindtj et al., 2018). Additionally, these discrepancies were ascribed to inadequate staff and inadequate knowledge on neonatal mortality data management.

It can be observed that, the key finding in this present study is the obvious revelation that stillbirth data though recorded more than $10 \%$ discrepancy rate in all data source compared, were collected more accurately $(87.5 \%)$ compared to neonatal mortalities $(0 \%)$. This is because, stillbirths are recorded by midwives in the delivery registers which is later collated onto monthly aggregated reports at the same service delivery point, whilst most neonatal mortalities data end up at the various children wards. This makes it sometimes difficult for midwives to follow up on these deaths and record accordingly in their collation sheets for further transcription unto monthly aggregated reports. This result in this present study provide supporting evidence that stillbirths are more likely to be reported compared to neonatal mortalities (Davies-tuck et al., 2017). However, this does not dispute the fact that the general knowledge of permanent 
staff on stillbirth data capture and collation during the three-year period under review maybe inadequate and that might have contributed to these inconsistencies. A fresher training on stillbirths and neonatal mortality data management will go a long way to equip these staff to improve on their data capturing and collation. It is of evidence that proper counting of stillbirths and neonatal mortality will improve maternal and child health decision making (The Lancet, 2011).

Table 2. Neonatal mortalities data accuracy and discrepancy by sampled facilities, Offinso North District, $2015-2017$

\begin{tabular}{|c|c|c|c|c|c|c|c|c|c|c|}
\hline \multirow[t]{2}{*}{$\begin{array}{l}\text { Health } \\
\text { Facility }\end{array}$} & $\begin{array}{c}\text { Registe } \\
\text { r }\end{array}$ & $\begin{array}{c}\text { Monthl } \\
\text { y } \\
\text { Midwiv } \\
\text { es } \\
\text { Returns } \\
\end{array}$ & $\begin{array}{c}\text { Accuracy } \\
\text { Ratio } \\
(\%)\end{array}$ & \multirow[t]{2}{*}{$\begin{array}{c}\text { Result } \\
\text { Interpret } \\
\text { ation }\end{array}$} & $\begin{array}{c}\text { Discrepa } \\
\text { ncy Rate } \\
(\%)\end{array}$ & $\begin{array}{l}\text { Monthl } \\
\text { y } \\
\text { Midwi } \\
\text { ves } \\
\text { Returns } \\
\end{array}$ & $\begin{array}{c}\text { DHIM } \\
\text { S2 }\end{array}$ & $\begin{array}{c}\text { Accura } \\
\text { cy } \\
\text { Ratio } \\
(\%)\end{array}$ & \multirow[t]{2}{*}{$\begin{array}{c}\text { Result } \\
\text { Interpret } \\
\text { ation }\end{array}$} & $\begin{array}{c}\text { Discrep } \\
\text { ancy } \\
\text { Rate } \\
(\%)\end{array}$ \\
\hline & [A] & [B] & $\begin{array}{l}\mathrm{A} / \mathrm{B}) \\
* 100 \\
{[\mathrm{C} 1]}\end{array}$ & & $\begin{array}{c}{[100-} \\
\text { C1] }\end{array}$ & [B] & [C2] & $\begin{array}{l}(\mathrm{B} / \mathrm{C}) \\
* 100 \\
{[\mathrm{C} 2]} \\
\end{array}$ & & $\begin{array}{c}{[100-} \\
\text { C2] }\end{array}$ \\
\hline $\begin{array}{l}\text { Facility } \\
\text { A }\end{array}$ & 0 & 0 & 100 & AR & 0 & 0 & 1 & 0 & OR & 100 \\
\hline $\begin{array}{l}\text { Facility } \\
\text { B }\end{array}$ & 0 & 0 & 100 & AR & 0 & 0 & 0 & 100 & AR & 0 \\
\hline $\begin{array}{l}\text { Facility } \\
\text { C }\end{array}$ & 1 & 0 & 0 & UR & 100 & 0 & 1 & 0 & OR & 100 \\
\hline Total & 1 & $\mathbf{0}$ & 0 & UR & 100 & $\mathbf{0}$ & 2 & 0 & OR & 100 \\
\hline
\end{tabular}

$\mathbf{A}=$ recounted data from register (primary source), $\mathbf{B}=$ facility monthly aggregated report, $\mathbf{C}=$ data reported in DHIMS2, $\mathbf{A R} \mathbf{1}=$ percentage accuracy between primary source and monthly aggregated reports, AR2= percentage of accuracy between monthly aggregated reports and DHIMS 2, DR1=percentage discrepancy between primary source and monthly aggregated reports, DR2= the percentage discrepancy between monthly aggregated reports and DHIMS 2, Under-reporting= Recounted data is greater than (>) $100 \%$ of facility summary Reported data, Over reporting=Recounted data is less than $(<) 100 \%$ of the facility summary Reported data, AR=Accurate Reporting, $\mathbf{U R}=$ Under Reporting, $\mathbf{O R}=$ Over Reporting

\section{Data completeness}

Data completeness in this study has been presented in two (2) segments. The first segment ascertained the submission of all monthly aggregated reports whilst the other segmented examined missing data on these monthly aggregated forms.

In this present study, all three (3)-health facilities had their monthly aggregated reports timely submitted to the District Health Directorate and duly entered into DHIMS 2 database. This was an excellent practice and greatly conforms to WHO definition on guideline for administrative report completeness (World Health Organization, 2012b). Facility A and Facility B recorded 100\% report submission for both actual (true) stillbirths and neonatal mortality data captured and recorded into DHIMS 2 database. Facility C however, recorded $99.3 \%$ for actual (true) neonatal mortality data captured and recorded into DHIMS 2 database. This was attributed to the fact that the facility recorded one neonatal mortality in the registers for the month of July 2017 but was not duly entered into DHIMS 2 database.

Table 3. Completeness of report submission by selected facilities, Offinso North District, 2015-2017

\begin{tabular}{|c|c|c|c|c|c|c|c|c|c|c|c|}
\hline \multirow{3}{*}{$\begin{array}{l}\text { Health } \\
\text { Facility }\end{array}$} & \multirow{2}{*}{\multicolumn{2}{|c|}{$\begin{array}{l}\text { Monthly } \\
\text { Midwives } \\
\text { Returns } \\
\text { submitted } \\
\text { to the next } \\
\text { level }\end{array}$}} & \multirow{2}{*}{\multicolumn{2}{|c|}{$\begin{array}{l}\text { Monthly } \\
\text { Midwives } \\
\text { Returns } \\
\text { completed on } \\
\text { DHIMS2 }\end{array}$}} & \multicolumn{4}{|c|}{$\begin{array}{c}\text { Neonatal Deaths or Stillbirths } \\
\text { data recorded on DHIMS }\end{array}$} & \multirow{3}{*}{$\begin{array}{c}\text { Total Report } \\
\text { Submission } \\
\text { Score }(\mathbf{A})\end{array}$} & \multirow{3}{*}{$\begin{array}{c}\text { Expected } \\
\text { Submission } \\
\text { Score (B) } \\
\mathrm{n}=144\end{array}$} & \multirow{3}{*}{$\begin{array}{l}\% \text { Report } \\
\text { Submission } \\
(\mathbf{A} / \mathbf{B}) * \mathbf{1 0 0}\end{array}$} \\
\hline & & & & & \multicolumn{2}{|c|}{$\begin{array}{l}\text { Neonatal } \\
\text { Mortalities }\end{array}$} & \multicolumn{2}{|c|}{ Stillbirths } & & & \\
\hline & Yes & No & Yes & No & Yes & No & Yes & No & & & \\
\hline $\begin{array}{l}\text { Facility } \\
\text { A }\end{array}$ & 36 & 0 & 36 & 0 & 36 & 0 & 36 & 0 & 144 & 144 & 100 \\
\hline $\begin{array}{l}\text { Facility } \\
\text { B }\end{array}$ & 36 & 0 & 36 & 0 & 36 & 0 & 36 & 0 & 144 & 144 & 100 \\
\hline $\begin{array}{l}\text { Facility } \\
\text { C }\end{array}$ & 36 & 0 & 36 & 0 & 35 & 1 & 36 & 0 & 143 & 144 & 99.3 \\
\hline
\end{tabular}




\section{$\boldsymbol{n}=$ expected total stillbirths and neonatal mortalities reports submissions to the next level}

The overall report submission completeness for all three (3)-health facilities used for this present study was 99.8\% as depicted on Table 3. The second section of data completeness focused on missing data elements on monthly aggregated reports submitted to the District Health Directorate and subsequently entered into DHIMS 2 database. Our finding in this present study revealed that, almost all three (3)-health facilities used for the study had the names of their facilities and reporting periods (Month and Year) clearly written on the monthly aggregated reports which were submitted to the District Health Directorate for the period under review. Surprisingly, none of the three (3) health facilities had its entire data elements filled out on the monthly aggregated reports submitted to the District Health Directorate for the period under review. It is a standard practice for facility in-charges to be aware of data or information leaving their catchment jurisdiction to the next level. To ascertain the evidence of final authorization of stillbirths and neonatal mortality by facility in-charges before transmission to the next level, their name and signature indicated on the aggregated reports were examined. In our study, the overall completeness for name and signature of health facility in-charges indicated on monthly aggregated reports was $67.9 \%$. This result strongly implies that facility in-charges sometimes do not supervise or consent to data or information sent from their service delivery points. However, the overall data completeness with respect to missing data for the three (3) health facilities was $72.4 \%$. This performance was attributed to the fact that some fields on the monthly aggregated reports were left blank. This violate the standard practice outline for data compilation and reporting (World Health Organization, 2012b). These blanks elements identified on aggregated reports in our study contradicts another study done in Victoria, Australia (Davies-tuck et al., 2017) but it is consistent with another study done in Tamale Metropolitan area (Badimsuguru, 2014). Further enquiry from the midwives revealed that those blank spaces found on almost all the monthly aggregated reports were supposed to be zero (0).

Table 4. Completeness (missing data elements) on monthly aggregated reports by sampled facilities, Offinso North, $2015-2017$

\begin{tabular}{|c|c|c|c|c|c|c|c|c|c|c|c|c|c|}
\hline \multirow[t]{2}{*}{$\begin{array}{l}\text { Health } \\
\text { Facility }\end{array}$} & \multicolumn{2}{|c|}{$\begin{array}{c}\text { Facility } \\
\text { Name } \\
\text { Indicated on } \\
\text { the } \\
\text { aggregated } \\
\text { report }\end{array}$} & \multicolumn{2}{|c|}{$\begin{array}{l}\text { Reporting } \\
\text { Period } \\
\text { Indicated } \\
\text { (Month, } \\
\text { Year) }\end{array}$} & \multicolumn{2}{|c|}{$\begin{array}{l}\text { Entire data } \\
\text { element } \\
\text { filled }\end{array}$} & \multicolumn{2}{|c|}{$\begin{array}{l}\text { Submission } \\
\text { date of } \\
\text { aggregated } \\
\text { report } \\
\text { Indicated }\end{array}$} & \multicolumn{2}{|c|}{$\begin{array}{l}\text { Name \& } \\
\text { signature of } \\
\text { facility head } \\
\text { indicated }\end{array}$} & \multirow[t]{2}{*}{$\begin{array}{c}\text { Total } \\
\text { Comple } \\
\text { teness } \\
\text { (A) }\end{array}$} & \multirow{2}{*}{$\begin{array}{c}\text { Expected } \\
\text { Total } \\
\text { Complete } \\
\text { ness (B) }\end{array}$} & \multirow[t]{2}{*}{$\begin{array}{c}\% \text { Data } \\
\text { completene } \\
\text { ss } \\
(\mathbf{A} / \mathbf{B})^{*} \mathbf{1 0 0}\end{array}$} \\
\hline & Yes & No & Yes & No & Yes & No & Yes & No & Yes & No & & & \\
\hline Facility A & 36 & 0 & 36 & 0 & 27 & 9 & 0 & 36 & 26 & 10 & 125 & 180 & 69.4 \\
\hline Facility B & 36 & 0 & 36 & 0 & 23 & 13 & 16 & 21 & 16 & 21 & 127 & 180 & 70.6 \\
\hline Facility C & 36 & 0 & 36 & 0 & 35 & 1 & 0 & 36 & 32 & 4 & 139 & 180 & 77.2 \\
\hline Total & 108 & 0 & 108 & 0 & 85 & 23 & 16 & 93 & 74 & 35 & 391 & 540 & 72.4 \\
\hline
\end{tabular}

$\boldsymbol{n}=$ expected completeness for selected data elements on monthly aggregated report submitted to the next level

This present study revealed an overall data completeness (report submissions and missing data elements) of $84.6 \%$ as depicted on figure 1. This findings is higher compared with a study done in Nigeria (Ogbuoji et al., 2016) which documented 65\% completeness. However, our findings for overall completeness is lower compared with another study in other part of Ghana (Amoakoh-coleman et al., 2015) 


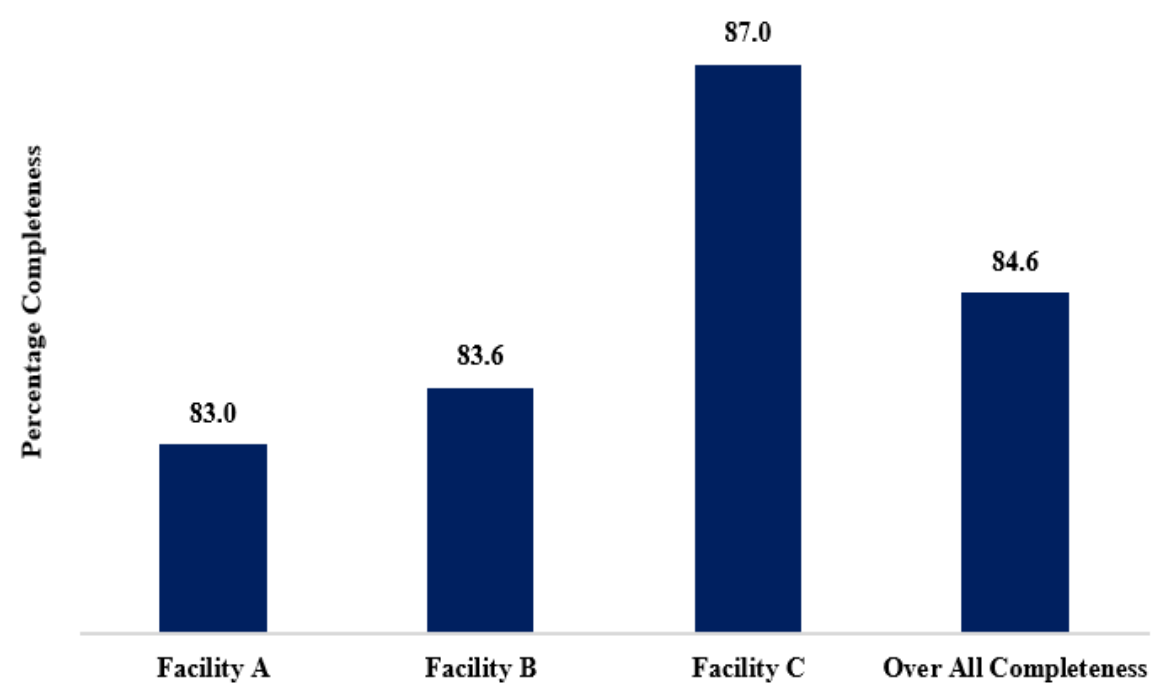

Figure 1. Overall of stillbirths and neonatal mortalities data completeness, 2015 - 2017, Offinso North District

\section{Data Availability and Storage}

In this present study all three (3) health facilities sampled had $100 \%$ availability for delivery registers and monthly aggregated reports physically present at the time of data collecction as illusstrated on Table 5 . Facility A could not make available their admission and discharge registers for 2015 hence was scored zero (0) for all twelve (12) months reviewed resulting in their admission and discharge register availability score of $66.7 \%$. This also affected their score $(66.7 \%)$ for the parameter which assessed whether registers were properly stored. This rule of scoring Facility A zero (0) for non availabilty of Admission and Discharge register for 2015, was necessary to lay more emphasis on ensuring the proper storage and accessibility of registers which is deemed to boost quality data validation (World Health Organization, 2012a). All three (3) health facilities assessed recorded $100 \%$ score for parameter that looked at how properly monthly aggregatead reports were filed. No electronic filing was detected thought the data collection period. However, manual filing of aggregated reports were neatly done in arc files and flat files in all three (3) health facilities assessed. All health facilities assessed, with exception of Facility A (86.7\%), recorded $100 \%$ availability and storage for soruce data and aggregated reports assessed as depicted on table 5.

Our pesent findings revealed an overall availability of $100 \%$ and $83.3 \%$ for delivery registers and admission and discharge registers respectively. These findings strongly implies all delivery registers for all the facilities sampled for this present study were readily available for the period under study. This made data easily accessible and easily retrieved (Pipino et al., 2002). However, same cannot be said about admission and discharge registers (83.3\% availability) which is the immediate source document for collating neonatal mortality data. The percentage availability for delivery registers in our study is however higher (100\%) compare to $98 \%$ as opined in a study to assess health facility data quality in Cambodia (World Health Organization, 2012a). This present study further revealed that, not all registers expected to be in place for the period under review were available (in the case of admission and discharge registers). This pattern of result is not consistent with a survey conducted in Ejisu Municipality which revealed a 100\% availability of all forms of registers for their period of study (Adamki et al., 2015). Monthly aggregated reports availability score $(100 \%)$ in our current findings is consistent with a study conducted in Mozambique (Gimbel et al., 2011). Furthermore, our study revealed a higher data availability compared to study conducted else where (Blencowe et al., 2015). 
Table 5. Data availability and storage by sampled facilities, Offinso North District, 2015-2017

\begin{tabular}{|c|c|c|c|c|c|c|c|c|c|c|c|c|c|c|c|c|c|c|}
\hline \multirow[t]{2}{*}{$\begin{array}{l}\text { Health } \\
\text { Facility }\end{array}$} & \multicolumn{3}{|c|}{$\begin{array}{l}\text { A\&D register } \\
\text { availability }\end{array}$} & \multicolumn{3}{|c|}{$\begin{array}{l}\text { Delivery } \\
\text { registers } \\
\text { availability }\end{array}$} & \multicolumn{3}{|c|}{$\begin{array}{c}\text { Monthly } \\
\text { Midwives } \\
\text { Returns (Form } \\
\text { A) availability }\end{array}$} & \multicolumn{3}{|c|}{$\begin{array}{c}\text { Register } \\
\text { properly stored } \\
?\end{array}$} & \multicolumn{3}{|c|}{$\begin{array}{c}\text { Form A } \\
\text { accurately } \\
\text { filed (monthly) }\end{array}$} & \multirow{2}{*}{$\begin{array}{c}\text { Tota } \\
\text { I } \\
\text { Avai } \\
\text { labili } \\
\text { ty \& } \\
\text { Stor } \\
\text { age } \\
\text { (A) }\end{array}$} & \multirow{2}{*}{$\begin{array}{c}\text { Expec } \\
\text { ted } \\
\text { Avail } \\
\text { ability } \\
\& \\
\text { Stora } \\
\text { ge }(B)\end{array}$} & \multirow{2}{*}{$\begin{array}{c}\% \\
\text { Availa } \\
\text { bility } \\
\& \\
\text { Storag } \\
\text { e } \\
\text { (A/B)* } \\
100\end{array}$} \\
\hline & Yes & $\begin{array}{l}\mathbf{N} \\
\mathbf{0}\end{array}$ & NA & Yes & $\begin{array}{l}\mathbf{N} \\
\mathbf{0}\end{array}$ & NA & Yes & $\begin{array}{l}\mathbf{N} \\
\mathbf{0}\end{array}$ & NA & Yes & N & NA & Yes & $\begin{array}{l}\mathbf{N} \\
\mathbf{0}\end{array}$ & NA & & & \\
\hline Facility A & 24 & 12 & 0 & 36 & 0 & 0 & 36 & 0 & 0 & 24 & 12 & 0 & 33 & 3 & 0 & 156 & 180 & 86.7 \\
\hline Facility B & 0 & 0 & 36 & 36 & 0 & 0 & 36 & 0 & 0 & 36 & 0 & 0 & 33 & 3 & 0 & 144 & 144 & 100 \\
\hline Facility C & 36 & 0 & 0 & 36 & 0 & 0 & 36 & 0 & 0 & 36 & 0 & 0 & 32 & 4 & 0 & 180 & 180 & 100 \\
\hline $\begin{array}{l}\text { Over All } \\
\text { Complete } \\
\text { ness }\end{array}$ & 60 & 12 & 36 & 108 & O & $\mathbf{0}$ & 108 & 0 & $\mathbf{0}$ & 96 & 12 & 0 & 98 & 10 & $\mathbf{0}$ & 480 & 504 & 95.2 \\
\hline
\end{tabular}

$A$-Total availability of source data, $B$-Total expected availability of source data, $(\boldsymbol{A} / \mathbf{B}) * 100$ - Total percentage availability and storage, $\mathbf{N A}=\mathrm{Not}$

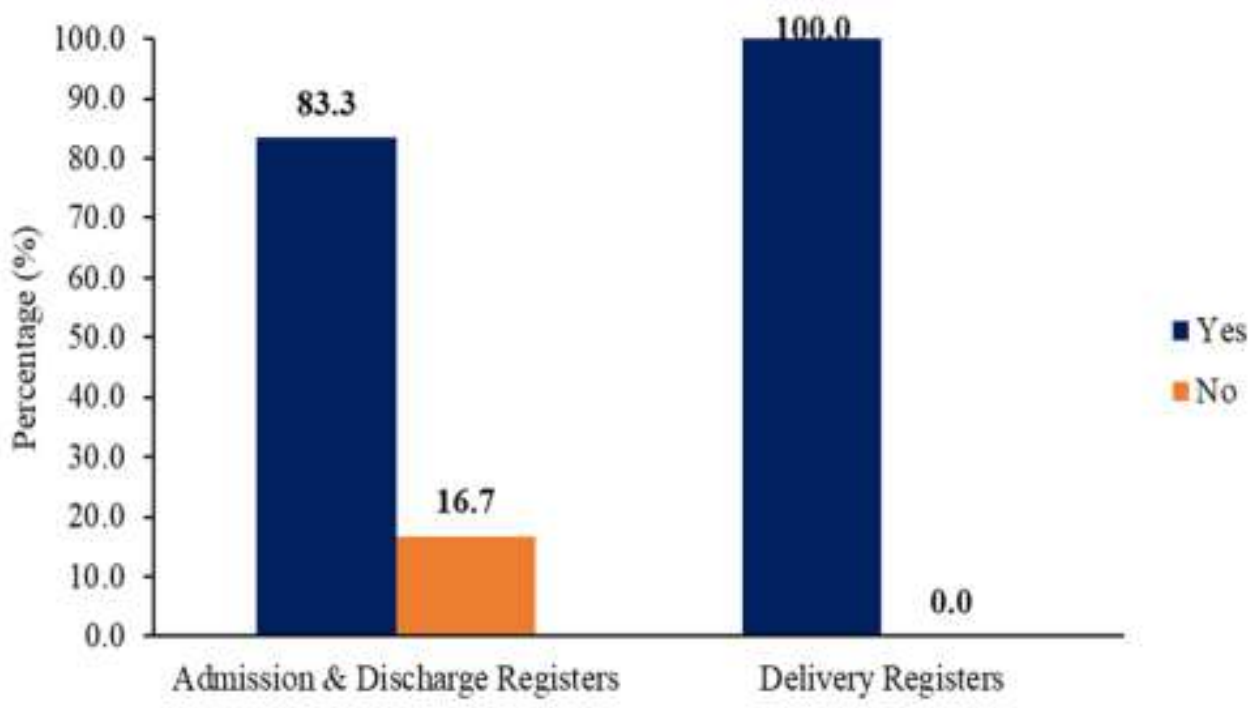

Applicable

Figure 2. Overall availability of delivery and admission register 2015 - 2017, Offinso North District

\section{Conclusions}

In conclusion, stillbirth data quality in the facilities assessed was generally good unlike neonatal mortalities. However, both stillbirth and neonatal mortalities data assessed were not reliable for decision-making per the verification factor of $10 \%$ or less explained above. Data completeness for all facilities assessed were generally good. Nevertheless, much emphasis should be placed on health facility heads' involvement in the supervision of all information that are submitted from their facilities to the next level.

Availability of delivery registers for the three (3) facilities assessed was excellent. However, misplaced admission and discharge registers for 2015 at Facility A should be a major concern for managers at the facility.

\section{Recommendation}


- Data Quality Audit teams should be instituted at all health facilities to validate monthly and quarterly data before submission to the next level.

- The District Health Directorate should provide additional storage space, cabinets, files, computers and accessories for health facilities to maintain good data storage and retrieval system in the district.

- The District Health Directorate and Sub-district heads should strengthen Facilitative Supervisory Visits (FSV) to all levels and give technical support to health staff who capture, collate and enter data on the importance of quality data management.

- Health facility heads or sub-district heads should make sure to duly supervised the monthly validation of all reports collated from their facilities and duly signed all reports before submitting to the next level to enhance accurate data capturing.

- Data quality assessment should be ritualized in the routine monitoring and support visits to all health facilities by the district level.

- Further research should be conducted to ascertain factors contributing high discrepancy rate of stillbirth and neonatal mortality data in the district.

\section{Ethics approval and consent to participate}

Ethical clearance was sought from the University of Health and Allied Sciences Research Ethics Committee (UHAS-REC A.6[79] 18-19). Permission was obtained from Offinso North District Health Directorate before the study was carried out. An introductory letter from the health Directorate was used to seek permission from the selected facilities before data collection. The study acknowledged all other sources of information used in reviewing literature. The study employed precautionary actions by ensuring that no direct identification information of sampled facilities was included. This was done to protect the identities of facilities whose data were collected. All data collected remain confidential and can be assessed with the principal investigator's consent.

\section{List of abbreviations}

$\begin{array}{ll}\text { CHAG } & - \text { Christian Health Association of Ghana } \\ \text { DHIMS } & - \text { District Health Information Management System } \\ \text { DQS } & - \text { Data Quality Self-Assessment } \\ \text { OTSS } & - \text { Outreach Training and Supportive Supervision } \\ \text { UHAS } & - \text { University of Health and Allied Sciences } \\ \text { WHO } & - \text { World Health Organisation }\end{array}$

\section{Data Availability}

Data used in this study is with the corresponding author and will be readily available upon request.

\section{Conflicts of Interest}

The authors declare that there is no conflict of interest regarding the publication of this paper

\section{Funding Statement}

The Authors received no external funding for this study.

\section{Authors' contributions}

This work was carried out in collaboration between all authors. Authors RN and WT conceived and designed the study. Authors RN and WT, wrote the protocol and the first draft of the manuscript. Authors $\mathrm{RN}$ and DN participated in the data collection. Authors RN, WK, SA, and DN analysed and interpreted the data. Authors RN, RA, SA and DN managed the literature searches. Authors RN, WK, SA and DN drafted the manuscript. All authors critically reviewed, revised and approved the final manuscript. 


\section{Acknowledgments}

We wish to extend our appreciation to the entire staff of Offinso North District for allowing and supporting us to conduct this study in the District. We also wish to express our profound gratitude to Hamza, Kenneth and Elorm for assisting us throughout the period of data collection.

\section{References}

1. Adamki, M., Asamoah, D., \& Riverson, K. (2015). Informatics Assessment of Data Quality on Expanded Programme on Immunization in Ghana : The Case of New Juaben Municipality. Health \& Medical Informatics, 6(4), 1-9. https://doi.org/10.4172/2157-7420.1000196

2. Amoakoh-coleman, M., Kayode, G. A., Brown-davies, C., Agyepong, I. A., Grobbee, D. E., Klipstein-grobusch, K., \& Ansah, E. K. (2015). Completeness and accuracy of data transfer of routine maternal health services data in the greater Accra region. BioMedical Central, 1-9. https://doi.org/10.1186/s13104-015-1058-3

3. Badimsuguru, A. B. (2014). Determinants of stillbirths in the Tamale Metropolitan area. University of Ghana, Legon.

4. Blencowe, H., Cousens, S., Jassir, F. B., Say, L., Chou, D., Mathers, C., Hogan, D., Shiekh, S., \& Qureshi, Z. U. (2015). National, regional , and worldwide estimates of stillbirth rates in 2015 , with trends from 2000: a systematic analysis. The Lancet Global Health, 4(2), 98-108. https://doi.org/10.1016/S2214-109X(15)00275-2

5. Davies-tuck, M. L., Davey, M., \& Wallace, E. M. (2017). Maternal region of birth and stillbirth in Victoria , Australia 2000 - 2011 :A retrospective cohort study of Victorian perinatal data. PLoS ONE, 12(6), 1-14. https://doi.org/10.1371/journal.pone.0178727

6. Engmann, C., Walega, P., Aborigo, R. A., Adongo, P., Moyer, C. A., Lavasani, L., Williams, J., Bose, C., Binka, F., \& Hodgson, A. (2012). Stillbirths and early neonatal mortality in rural Northern Ghana. Tropical Medicine and International Health Volume, 17(3), 272-282. https://doi.org/10.1111/j.1365-3156.2011.02931.x

7. Ghana Health Service. (2017). Offinso North DHIMS Malaria Indicators.

8. Ghana Health Service. (2019). Offinso North Health Directorate Annual Report.

9. Gimbel, S., Micek, M., Lambdin, B., Lara, J., Karagianis, M., Cuembelo, F., Gloyd, S. S., Pfeiffer, J., \& Sherr, K. (2011). An assessment of routine primary care health information system data quality in Sofala Province , Mozambique. Population Health Metrics, 9(1), 12. https://doi.org/10.1186/14787954-9-12

10. Hure, A. J., Chojenta, C. L., Powers, J. R., Byles, J. E., \& Loxton, D. (2015). Validity and Reliability of Stillbirth Data Using Linked Self-Reported and Administrative Datasets. J Epidemiol, 25(1), 30 37. https://doi.org/10.2188/jea.JE20140032

11. Kusre, G., \& Baruah, J. (2016). Missing stillbirth data: A hospital based study. International Journal of Community Medicine and Public Health |, 3(10), 2949-2952. https://doi.org/10.18203/23946040.ijcmph20163389

12. Lindtj, B., Mitike, D., Zidda, Z., \& Yaya, Y. (2018). Reducing stillbirths in Ethiopia :Results of an intervention programme. PLOS ONE, 13(5), 1-11. https://doi.org/10.1371/journal.pone.0197708

13. Mouroutis, S. (2015). Data Management: Evaluation of an aspect of Data. Research Gate, February, $1-8$.

14. Ogbuoji, O., Olapeju, B., Makinde, O. A., \& Babalola, S. (2016). Trends in the completeness of birth registration in Nigeria: 2002 -2010. Demographic Research, 35(12), 315-338. https://doi.org/10.4054/DemRes.2016.35.12

15. Patel, J. (2015). Data Quality Management - Tools and Techniques. C S Journalss, 7, 198-201.

16. Pipino, L. L., Lee, Y. W., \& Wang, R. Y. (2002). Data Quality Assessment. Communications of the ACM, 45(4), 211-218.

17. Sidi, F., Hassany, P., Panahy, S., Affendey, L. S., Jabar, M. A., \& Ibrahim, H. (2013). Data quality: A survey of data quality dimensions. Research Gate. https://doi.org/10.1109/InfRKM.2012.6204995 
18. The Lancet. (2011, April). Stillbirths: An Executive Summary for The Lancet's Series. The Lancet, $1-8$.

19. World Health Organization. (2012a). Assessment of health facility data quality Data quality report card:Data quality report card Cambodia.

20. World Health Organization. (2012b). Guide to the health facility: Data quality report card.

21. World Health Organization (WHO). (2016). Making Every Baby Count Audit and review of stillbirths and neonatal deaths (pp. 1-136). World Health Organization Publications. 